\title{
Anterior Surface of the Stomach
}

National Cancer Institute

\section{Source}

National Cancer Institute. Anterior Surface of the Stomach. NCI Thesaurus. Code C32111.

The anterior aspect of the stomach. 